\title{
Consequences of microbial diversity in forest nitrogen cycling: diverse ammonifiers and specialized ammonia oxidizers
}

\author{
Kazuo Isobe ${ }^{1} \cdot$ Yuta Ise $^{1} \cdot$ Hiroyu Kato ${ }^{1} \cdot$ Tomoki Oda $^{1} \cdot$ Christian E. Vincenot ${ }^{2} \cdot$ Keisuke Koba $\mathbb{D}^{3}$. \\ Ryunosuke Tateno ${ }^{4} \cdot$ Keishi Senoo ${ }^{1,5} \cdot$ Nobuhito Ohte $^{2}$
}

Received: 15 April 2019 / Revised: 6 August 2019 / Accepted: 14 August 2019 / Published online: 3 September 2019

(c) The Author(s) 2019. This article is published with open access

\begin{abstract}
We tested the ecosystem functions of microbial diversity with a focus on ammonification (involving diverse microbial taxa) and nitrification (involving only specialized microbial taxa) in forest nitrogen cycling. This study was conducted on a forest slope, in which the soil environment and plant growth gradually changed. We measured the gross and net rates of ammonification and nitrification, the abundance of predicted ammonifiers and nitrifiers, and their community compositions in the soils. The abundance of predicted ammonifiers did not change along the soil environmental gradient, leading to no significant change in the gross ammonification rate. On the other hand, the abundance of nitrifiers and the gross nitrification rate gradually changed. These accordingly determined the spatial distribution of net accumulation of ammonium and nitrate available to plants. The community composition of predicted ammonifiers gradually changed along the slope, implying that diverse ammonifiers were more likely to include taxa that were acclimated to the soil environment and performed ammonification at different slope locations than specialized nitrifiers. Our findings suggest that the abundance of ammonifiers and nitrifiers directly affects the corresponding nitrogen transformation rates, and that their diversity affects the stability of the rates against environmental changes. This study highlights the role of microbial diversity in biogeochemical processes under changing environments and plant growth.
\end{abstract}

\section{Introduction}

The role of microbial diversity in ecosystem functions has been a focus of debate [1-3]. However, most ecologists typically assume that a diverse community has greater functional redundancy than a community compromising

Supplementary information The online version of this article (https:// doi.org/10.1038/s41396-019-0500-2) contains supplementary material, which is available to authorized users.

Kazuo Isobe

akisobe@mail.ecc.u-tokyo.ac.jp

1 Graduate School of Agricultural and Life Sciences, The University of Tokyo, Tokyo, Japan

2 Graduate School of Informatics, Kyoto University, Kyoto, Japan

3 Center for Ecological Research, Kyoto University, Kyoto, Japan

4 Field Science Education and Research Center, Kyoto University, Kyoto, Japan

5 Collaborative Research Institute for Innovative Microbiology, The University of Tokyo, Tokyo, Japan specialized taxa $[4,5]$. This assumption has been developed by theoretical or empirical studies of macroorganisms, such as plants and animals [6-8]. Microbial ecological studies, testing whether more diverse microbial communities are more functionally redundant, that is, whether changes in community composition less likely correspond with changes in functional rates [3], can support this assumption [9-11]. However, such studies have been mostly limited to small-scale experiments (e.g., soil microcosm experiments in laboratories) with the microbial diversity being experimentally manipulated.

Microbes dominate the biogeochemistry of ecosystems by virtue of their numbers and metabolic capabilities $[12,13]$. Thus, we could expect that the greater functional redundancy of diverse microbial communities, if true, affects biogeochemical cycling in an ecosystem. Based on the assumption of microbial functional redundancy, Schimel [14] proposed that, because nitrogen $(\mathrm{N})$ cycling and carbon (C) cycling comprise broad (involving diverse microbial taxa) and narrow (involving only specialized microbial taxa) processes, the broad processes may be more stable against environmental change than the narrow ones. 
However, this has rarely been tested at the terrestrial ecosystem level $[15,16]$.

Nitrogen supply to plants via microbial metabolic functions can limit plant productivity in temperate forests [17]. Ammonium produced by ammonifying microbes and $\mathrm{NO}_{3}{ }^{-}$ produced by nitrifying microbes are the main $\mathrm{N}$ species in the soil available to plants. Ammonifying microbes, which generate $\mathrm{NH}_{4}{ }^{+}$from organic $\mathrm{N}$ monomers, are considered more phylogenetically diverse than nitrifying microbes, which oxide $\mathrm{NH}_{3} / \mathrm{NH}_{4}{ }^{+}$to $\mathrm{NO}_{2}{ }^{-} / \mathrm{NO}_{3}{ }^{-}$[18-20]. Moreover, we could expect that most soil microbes regardless of their phylogeny participate in ammonification. Taking up organic $\mathrm{N}$ monomers is an essential metabolic process for microbes, and deaminases and deamidases that generate the precursors of $\mathrm{NH}_{4}{ }^{+}$are active inside living microbes [18-20]. Conversely, nitrifying microbes, in particular, autotrophic and aerobic $\mathrm{NH}_{3}$-oxidizing microbes that mediate the ratelimiting step of nitrification, are phylogenetically and metabolically limited within the phyla Proteobacteria $\left(\mathrm{NH}_{3}-\right.$ oxidizing bacteria), Thaumarchaeota $\left(\mathrm{NH}_{3}\right.$-oxidizing archaea), and potentially Nitrospirae (recently found comammox bacteria) [21, 22]. Thus, if a more diverse microbial community has greater functional redundancy, we could expect that ammonification would be more stable against environmental change than nitrification, and such differences could affect the availability of soil $\mathrm{N}$ to plants.

The abundance of microbes possessing specialized functions is frequently correlated with the rates of the ecosystem processes that they perform, such as carbon degradation [23], $\mathrm{NH}_{4}^{+}$production [24], nitrification [25-27], and denitrification [28]. In contrast, many studies that have assessed the overall microbial community composition (or diversity) and ecosystem process rates have not reported a direct link between them [29]. A recent meta-analysis found that the inclusion of community composition as a predictor of $\mathrm{C}$ - and $\mathrm{N}$-cycling process rates improved predictive power in only $29 \%$ of considered studies [30]. Thus, we hypothesized that the abundance of microbes possessing specialized functions directly affects the corresponding ecosystem process rates, and that their diversity affects the stability of the process against environmental changes.

This study aimed to test the aforementioned hypotheses with a focus on ammonification and nitrification, which influence plant productivity [17], in a forest. We conducted this study on a steep forest slope wherein soil hydrological and chemical properties and plant productivity gradually change at a small scale. We specifically analyzed the effects of the following variables: (1) the soil environmental gradient on gross ammonification and nitrification rates with the change in the abundance of ammonifiers and nitrifiers, (2) differences in the phylogenetic diversity of ammonifiers and nitrifiers on the stability of gross ammonification and nitrification rates, and (3) the identified relationships (i.e., 1 and 2) on ammonium and nitrate contents available to plants (i.e., net ammonification and nitrification rates) in the soils.

\section{Materials and methods}

\section{Study site}

The study was conducted in a planted coniferous forest in the Fukuroyamasawa Experimental Watershed located in The University Forest in Chiba, the University of Tokyo, Japan $\left(35^{\circ} 12^{\prime} \mathrm{N}, 140^{\circ} 06^{\prime} \mathrm{E}\right)$. The forest is located in a temperate climatic region and a mountainous area at an elevation of 124-227 MASL. The mean annual precipitation and air temperature (1994-2003) were $2230 \mathrm{~mm}$ and $14{ }^{\circ} \mathrm{C}$, respectively [31].

We established a $10 \times 100-\mathrm{m}^{2}$ study plot in September 2013 on a steep slope (ca. $30^{\circ}$ ) from the ridge to the valley in a small-scaled (1.09 ha) watershed (Fig. S1). The evergreen coniferous tree species Cryptomeria japonica was planted from 1928 to 1930 . The growth rate of the tree species increases down the slope. The height was $19.2 \pm$ $4.2 \mathrm{~m}(n=44)$ around the upper end of the slope and $26.9 \pm$ $5.0 \mathrm{~m}(n=129)$ around the lower end of the slope $(100 \mathrm{~m}$ from the ridge). The diameter at breast height was $30.8 \pm$ $10.5 \mathrm{~cm}$ around the upper end and $37.7 \pm 13.0 \mathrm{~cm}$ around the lower end [31]. The volumetric soil water content at a $10-\mathrm{cm}$ depth at the ridge and valley was monitored over time during the actively growing season of trees [32] from May 11, 2014 to August 4, 2014 using time domain reflectometry. The details are described in the Supplementary Methods.

\section{Soil sampling and chemical analysis}

Soil sampling was conducted twice (September 2013 and August 2014). We sampled $\sim 200 \mathrm{~g}$ of soil from the surface $0-10 \mathrm{~cm}$ deep in the mineral layer (A horizon). In September 2013, we sampled 55 soil samples at 11 points (every $10 \mathrm{~m}$ from the ridge to the valley) with five replicates at each point by sampling every $2 \mathrm{~m}$ from the left to right side (Fig. S1). In August 2014, we sampled ten soil samples at the ridge and valley (100 $\mathrm{m}$ from the ridge) with five replicates. The soils were sieved through a $2-\mathrm{mm}$ mesh. Soil sampled in September 2013 was used to survey the spatial variations of $\mathrm{N}$ biogeochemical properties, microbial abundances, and microbial community compositions. Soil sampled in August 2014 was used in the water manipulation experiment.

The water content, $\mathrm{pH}, \mathrm{NH}_{4}{ }^{+}$content, $\mathrm{NO}_{3}{ }^{-}$content, and dissolved organic nitrogen (DON) and carbon (DOC) contents of soils were measured, the details of which are described in the Supplementary Methods. 


\section{Measurement of the gross and net ammonification and nitrification rates}

We determined the gross and net rates of ammonification and nitrification in the soils. The gross rates are the actual rates, and thus are reflected directly by the microbial reactions of ammonification and nitrification [33]. The net rates (or the net accumulation of $\mathrm{NH}_{4}{ }^{+}$and $\mathrm{NO}_{3}{ }^{-}$in the absence of plant roots) are the excess $\mathrm{N}$ after the microbial consumption of produced $\mathrm{NH}_{4}{ }^{+}$and $\mathrm{NO}_{3}{ }^{-}$, and thus are thought to provide a good index of $\mathrm{N}$ availability to plants [33].

The gross ammonification and nitrification rates in soil samples were determined during $24 \mathrm{~h}$ of incubation using the isotope dilution method [33]. The net ammonification and nitrification rates were calculated as the concentration changes in soil $\mathrm{NH}_{4}{ }^{+}$and $\mathrm{NO}_{3}{ }^{-}$, respectively, without ${ }^{15} \mathrm{~N}$ addition during the 28-day incubation. The measurement followed previously described methods [34, 35], the details of which are described in the Supplementary Methods.

\section{Quantification of 165 rRNA gene, bacterial and archaeal amoA, and bacterial nirk}

We hypothesized that we could consider almost all bacteria to be ammonifiers because $\mathrm{NH}_{4}{ }^{+}$production can occur via the assimilation of small organic $\mathrm{N}$ compounds that all bacteria can facilitate [19, 20]. We analyzed ammoniaoxidizing bacteria and archaea as nitrifiers, which are responsible for ammonia oxidation, the rate-limiting step of nitrification [36], and nitrite-reducing bacteria as denitrifiers, which are responsible for the indispensable step of denitrification, namely, the reduction of soluble nitrite to gaseous nitric oxide [37].

Microbial DNA was extracted from the soils and purified as described previously [27]. Abundances of the bacterial $16 \mathrm{~S}$ rRNA gene, bacterial and archaeal ammonia monooxygenase genes $(a m o A)$, and bacterial copper-containing reductase gene (nirK) were quantified by qPCR to estimate the abundances of total bacteria, bacterial and archaeal nitrifiers, and bacterial denitrifiers, respectively. The quantification followed the methods described by Isobe et al. [38], and the details are described in the Supplementary Methods.

\section{Sequence analysis of 16S rRNA gene}

Bacterial 16S rRNA genes in soils were PCR-amplified using the primers $515 \mathrm{f}-806 \mathrm{r}$. These primers were identical to those used in the qPCR assay, except for the addition of appropriate Illumina adapters and 12-bp barcodes for multiplex sequencing on the Illumina platform [39]. PCR amplification, sequencing, and sequence analysis followed the methods described by Isobe et al. [38], the details of which are described in the Supplementary Methods. The
UPARSE pipeline [40] was used to merge the demultiplexed sequences, conduct quality filtering, and cluster sequences into operational taxonomic units (OTUs) at $>97 \%$ sequence similarity. The number of sequences per sample was rarefied to 17,800 via random sampling within the QIIME pipeline [41]. The OTUs' sequences were aligned with PyNAST, and a phylogenetic tree was constructed with FastTree after the aligned sequences were filtered with the default lanemask file within QIIME.

PCR primers for quantifying the abundances of microbial genes responsible for ammonification have not been developed, unlike amoA in nitrification and nirK and nirS in denitrification. Thus, to estimate the abundance and composition of these microbial genes, we used Phylogenetic Investigation of Communities by Reconstruction of Unobserved States (PICRUSt) [42], which was designed to computationally infer metagenome functional contents from $16 \mathrm{~S}$ rRNA gene sequences. The detailed procedures are described in the Supplementary Methods. We predicted the occurrence of the gene necessary for extracellular enzymes to degrade plant litter or dead microbes, namely, $\mathrm{N}$-acetylglucosaminidase (EC 3.2.1.52). We also predicted the occurrence of the genes necessary for intracellular enzymes for $\mathrm{NH}_{3}$ production, namely, arginase (EC 3.5.3.1) and urease (EC 3.5.1.5). The reactions of these enzymes can be considered as rate-limiting steps of ammonification, and thus are frequently measured to estimate microbial ammonification activity [43]. Furthermore, the presence of $\mathrm{N}$ acetylglucosaminidase gene is known to be phylogenetically conserved [44], and thus 16S rRNA gene-based phylogeny may enable estimation of the production capability at relatively high probability.

\section{Clone library analysis of bacterial and archaeal amoA}

To estimate the community composition of nitrifiers, we filtered the ammonia oxidizers' OTUs based on their $16 \mathrm{~S}$ rRNA gene-based taxonomic information. Accordingly, we found that our sequence data possessed the OTUs of the known archaeal or bacterial ammonia oxidizers. However, those OTUs were not detected in the upper slope. Therefore, we performed small-scaled clone library analysis of their amoA sequences and compared the community composition of nitrifiers in the upper and lower slopes. We used microbial DNA extracted from one soil sample each from the ridge and valley. The bacterial and archaeal amoA sequences were amplified with the primers used in the qPCR assay, which obtained 37 and 40 bacterial amoA clones and 48 and 47 archaeal amoA clones from the ridge and valley, respectively. Then, we obtained three and four bacterial amoA OTUs and six and eleven archaeal amoA OTUs from the ridge and valley, respectively. PCR 
amplification, Sanger sequencing, OTU clustering ( $>97 \%$ sequence similarity), and phylogenetic analysis followed the methods described by Isobe et al. [26], details of which are described in the Supplementary Methods.

\section{Water manipulation experiment}

We expected from the results of the survey of the spatial variations that soil water content strongly affects the abundance of nitrifiers and the nitrification rate in soil, but does not affect the bacterial community composition. Thus, we monitored their abundance and $\mathrm{NO}_{3}{ }^{-}$content in soil with/without experimental water addition. We used the three soil sets: soils taken at the ridge (dry soils, $23 \%$ soil water content on average), soils taken at the valley (wet soils, $43 \%$ ), and soils taken at the ridge with water added to the same level as that in soils at the valley (wet soils, 43\%). Twenty grams of soil were dispensed into the glass vessels covered with aluminum foil to minimize water evaporation and incubated for $0,14,28,42$, or 84 days at $20^{\circ} \mathrm{C}$ in the dark. Water loss was replenished at these days. Then, the soil nitrate content was measured. The bacterial and archaeal amoA and 16S rRNA gene abundances were measured at 0,42 , and 84 days. The $16 \mathrm{~S}$ rRNA gene was sequenced at 0 and 84 days and rarefied at 13,000 sequences. All analyses including gene quantification and the sequence analysis of 16S rRNA gene were conducted as described above.

\section{Statistical analysis}

The details are described in the Supplementary Methods. Briefly, the relationships of the slope position with the measured variables were tested via correlation analysis. Structural equation modeling (SEM [45]) was used to determine the effects of soil environmental gradient on ammonification and nitrification rates by affecting the abundance of ammonifiers and nitrifiers. We tested the simple hypothetical relationship involving the gross ammonification and nitrification rates being determined by the abundance of ammonifiers and nitrifiers as well as the substrate for the processes, and the abundance of ammonifiers and nitrifiers being determined by soil environmental properties (i.e., soil $\mathrm{pH}$ and water content) as well as the substrate. Spatial change in the community composition was visualized via a nonmetric multidimensional scaling (NMDS) ordination with Bray-Curtis similarities. Then, the community composition was statistically compared among the slope positions via a permutational multivariate analysis of variance (PERMANOVA) test. The Bray-Curtis similarity between two communities was also statistically compared with the geographic distance between the communities via a Mantel test. The soil environmental variables that strongly correlated with the compositional similarity were tested for significance based on a permutation test.

\section{Results}

\section{Soil environmental properties}

Soil water content increased down the slope from $21.4 \%$ at the ridge to $40.8 \%$ at the valley $(R=0.71, p<0.001$, Fig. 1). The soils at the ridge were constantly drier than those at the valley over $\sim 3$ months of observation (Fig. S1). Soil $\mathrm{pH}$ also increased down the slope from 5.2-5.6 at the ridge to 5.9-6.2 at the valley $(R=0.62, p<0.001$, Fig. 1$)$. Soil water content increased more linearly than soil $\mathrm{pH}$.

\section{$\mathrm{N}$ transformations}

Soil $\mathrm{NO}_{3}{ }^{-}$content increased down the slope $(R=0.56, p<$ 0.001 , Fig. 1), whereas no consistent increase or decrease was noted for soil $\mathrm{NH}_{4}{ }^{+}$content $(R=0.13, p=0.34$, Fig. 1). Soil DON content did not exhibit a consistent spatial change $(R=-0.07, p=0.60$, Fig. 1$)$, but soil DOC content $(R=-0.31, p=0.02$, Fig. 1$)$ and DOC/DON $(R=$ $-0.53, p<0.001$, Fig. 1$)$ decreased down the slope.

Net ammonification and nitrification rates along the slope were within the range of variation in the rates of forests in Japan ( -0.16 to 0.98 and 0.0 to $3.00 \mathrm{mg} \mathrm{N} \mathrm{kg}^{-1} \mathrm{~d}^{-1}, N=38$ [46]). Gross ammonification and nitrification rates along the slope were also within the range of variation in the rates of forests in Japan ( 0.82 to 15.83 and 0.04 to $3.78 \mathrm{mg} \mathrm{N} \mathrm{kg}^{-1} \mathrm{~d}^{-1}$, $N=38$ [46]). The net ammonification rate decreased down the slope $(R=-0.43, p<0.001$, Fig. 1), exhibiting positive values for the upper slope ( 0 to $40 \mathrm{~m}$ from the top) and negative values for the lower slope (80 to $100 \mathrm{~m}$ from the top). Conversely, the net nitrification rate increased down the slope ( $R=0.61, p<0.001$, Fig. 1), being positive for the lower slope (40-100 $\mathrm{m}$ from the top). The gross ammonification rate did not display a consistent spatial change $(R=-0.10, p=$ 0.48 , Fig. 1), but the gross nitrification rate increased down the slope $(R=0.57, p<0.001$, Fig. 1$)$.

\section{Microbial abundances}

The abundance of the 16S rRNA gene did not exhibit a consistent spatial change $(R=0.48, p=0.08$, Fig. 1$)$, but the abundances of both archaeal and bacterial amoA increased down the slope ( $R=0.52$ for archaeal amo $A, R=$ 0.48 for bacterial amoA, $p<0.001$ for both, Fig. 1). Archaeal $a m o A$ was more abundant than bacterial amoA at all locations along the slope. The abundance of bacterial nirK also increased down the slope $(\mathrm{R}=0.54, p<0.001$, Fig. 1). We assumed that most bacteria can participate in 

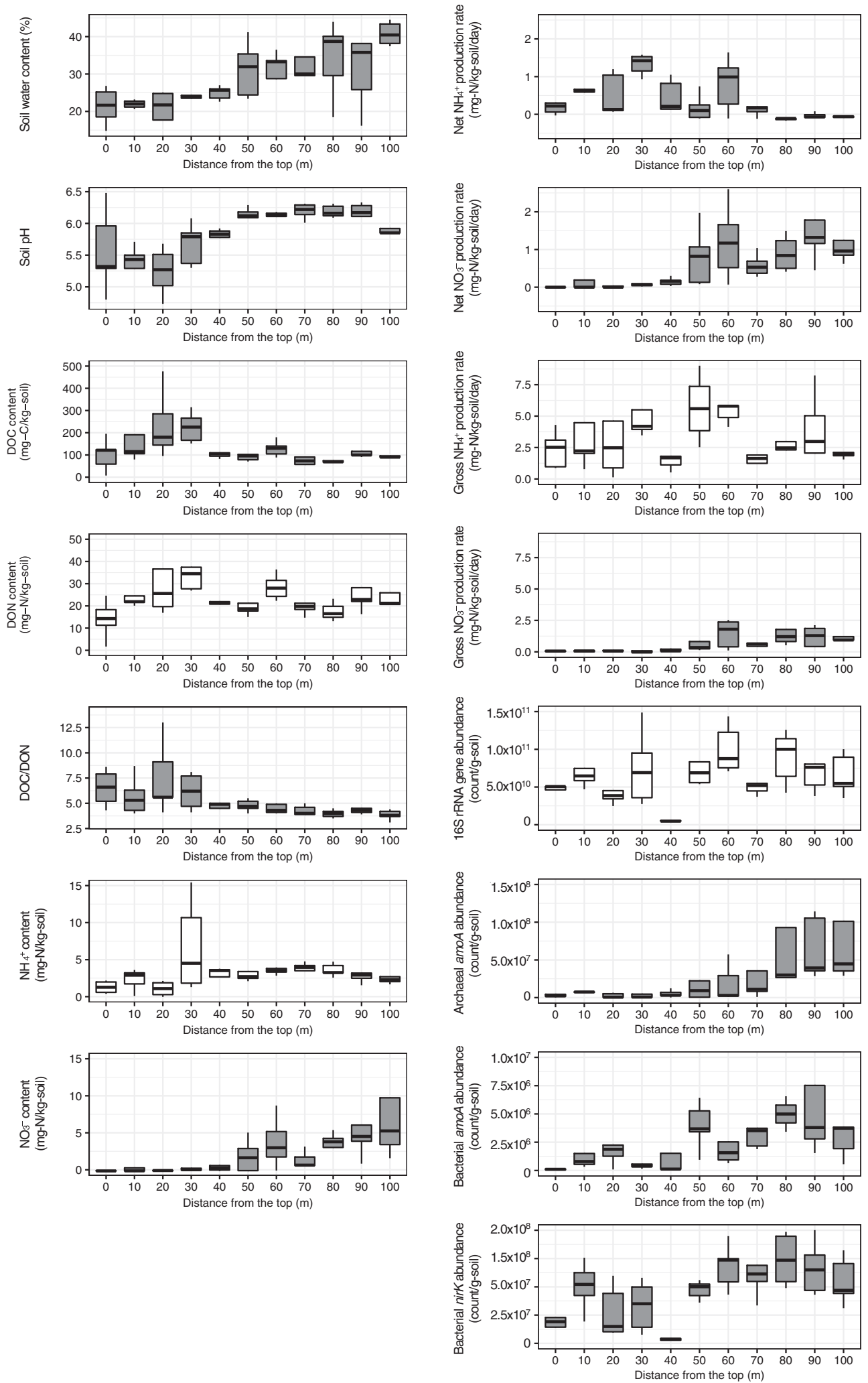

Fig. 1 Soil environmental properties, nitrogen transformation rates, and microbial gene abundances along the forest slope. The variables exhibiting significant relationships with the location on the forest slope are displayed in gray $(p<0.05)$ 
ammonification, and observed a weak but positive correlation between the abundance of 16S rRNA gene and the gross ammonification rate $(R=0.34, p=0.01)$. We also observed a positive correlation between the abundance of archaeal amoA and gross nitrification rate $(R=0.45, p<$ 0.001 ), but not between the abundance of bacterial amoA and gross nitrification rate $(R=0.20, p=0.16)$.

\section{Relationships among soil environmental properties, microbial abundances, and $\mathbf{N}$ transformations}

We examined the relationships among the soil environmental properties, microbial abundances, and $\mathrm{N}$ transformations by using the SEM. SEM revealed that the gross ammonification rate was most strongly affected by the soil DON content (effect size $=0.50, p<0.01$, Fig. 2), followed by the abundance of total bacteria (effect size $=0.27, p<$ 0.01 , Fig. 2). The abundance of total bacteria was affected by the soil water content (effect size $=0.39, p<0.01$, Fig. 2), but not by the substrate/energy source (soil DOC or DON content). The gross nitrification rate was affected solely by the abundance of nitrifiers (effect size $=0.83, p<$ 0.01 , Fig. 2). The abundance of nitrifiers was strongly affected by the soil water content (effect size $=0.82, p<$ 0.01 , Fig. 2), but not by the substrate/energy source (soil $\mathrm{NH}_{4}{ }^{+}$content).

\section{Microbial community composition}

From the 16S rRNA gene sequences rarefied to 17,800 sequences, 10,651 OTUs were obtained. The microbial community was dominated by the phyla Proteobacteria and
Acidobacteria, followed by Actinobacteria, Verrucomicrobia, and Planctomycetes (Fig. S2). The alpha diversity represented by the number and Shannon diversity index of OTUs in 17,800 sequences increased down the slope (Fig. S3). The overall community composition shifted along the slope (PERMANOVA: $R=0.47, p<0.001$, Fig. 3 ) and community compositions at more distant locations became more different (Mantel test for Bray-Curtis similarity: $R=-0.428, p<0.001$, Fig. S4). When exploring the soil environmental variables most strongly correlated with the compositional similarity, soil $\mathrm{pH}$ was the largest factor influencing the composition $(R=$ $0.64, p<0.001)$, followed by soil $\mathrm{NH}_{4}^{+}$content $(R=0.55$, $p=0.001)$ and soil DOC/DON $(R=0.39, p=0.04)$.

PICRUSt estimated counts of the genes based on the 17,800 rarefied $16 \mathrm{~S}$ rRNA gene sequences, tagged with KEGG Orthology. We then extracted the counts of K01207 for $\mathrm{N}$-acetylglucosaminidase, K01476 for arginase, and K01427 for urease (subunit alpha). The Nearest Sequenced Taxon Index score for our PICRUSt analysis was $0.21 \pm$ $0.02 \mathrm{sd}(N=55)$, slightly higher than values in the soils $(0.17 \pm 0.02 \mathrm{sd})$ described in the paper by Langille et al. [42], the original publication of PICRUSt that showed relatively accurate functional gene predictions.

The OTUs predicted to possess the genes necessary for $\mathrm{N}$-acetylglucosaminidase, arginase, and urease production were mapped onto the phylogenetic tree, illustrating that they were widely distributed throughout the different phyla (Fig. 4). The absolute abundance of those OTUs, estimated by the counts of the gene multiplied by the abundance of $16 \mathrm{~S}$ rRNA gene in the soil, did not display spatial changes along the slope (Fig. S5), but it exhibited a positive correlation with the gross ammonification rate $(R=0.31$,
Fig. 2 Hierarchical relationship among soil environmental properties, microbial abundances, and nitrogen transformations. The path diagrams represent the full and final models used to describe the relationship between the gross ammonification rate (a) and gross nitrification rate (b). The numbers associated with the arrows between two variables are the partial regression coefficients derived from multiple regressions. The solid and dashed arrows were significant $(p<0.05)$ and insignificant in the final model, respectively
A

Soil $N$ properties

Microbial abundance

Microbial abundance

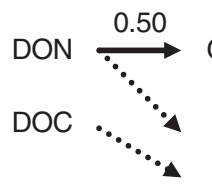

Gross ammonification rate 0.27

Total bacteria

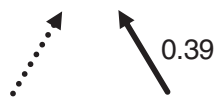

Soil environmental properties

Soil $\mathrm{pH}$

Water Content
B

Soil $N$ properties<smiles>CC(C)[14CH3]</smiles>

Gross $\mathrm{NO}_{3}{ }^{-}$production rate $\ldots . . . \vee \mathrm{NO}_{3}{ }^{-}$ 0.83

Microbial abundance

$\mathrm{NH}_{3}$ oxidizing archaea

$\mathrm{NH}_{3}$ oxidizing bacteria 

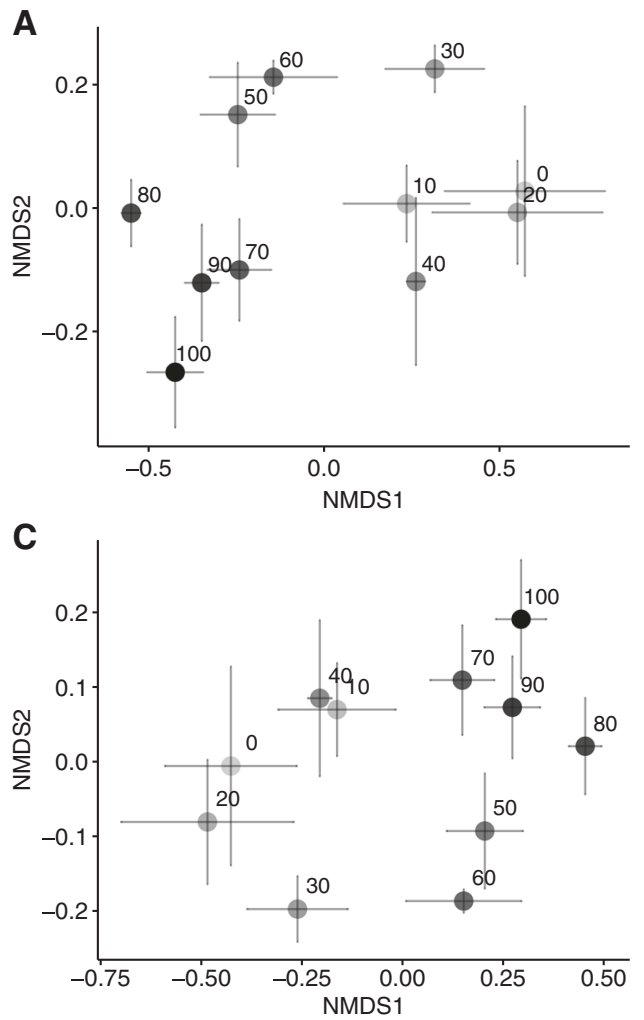

Fig. 3 Nonmetric multidimensional scaling ordination showing the change in the composition of total bacterial community (a) and operational taxonomic units predicted to possess the genes for $\mathrm{N}$ -

$p=0.02$ for $N$-acetylglucosaminidase; $R=0.31, p=0.02$ for arginase; $R=0.36, p<0.01$ for urease). The compositions of those OTUs shifted along the slope (PERMANOVA: $R=0.47, p<0.001$ for $N$-acetylglucosaminidase; $R=0.47, p<0.001$ for arginase; $R=0.48, p<0.001$ for urease, Fig. 3; Mantel test for Bray-Curtis similarity: $R=$ $-0.40, p<0.001$ for $N$-acetylglucosaminidase; $R=-0.40$, $p<0.001$ for arginase; $R=-0.39, p<0.001$ for urease, Fig. S4). The relative abundance of 1159 and 2273 OTUs increased up the slope and down the slope, respectively (linear regression, $p<0.1$, Table 1), suggesting that they became more dominant in the community in the upper and lower parts, respectively. A substantial proportion of them was predicted to possess the genes necessary for ammonification (Table 1).

The OTUs identified as ammonia oxidizers based on their 16S rRNA gene-based taxonomy were also mapped onto the phylogenetic tree (Fig. 4). Unlike ammonifiers, these OTUs were located in specific phylogenetic branches. The relative abundance of these OTUs increased down the slope $(R=$ $0.70, p<0.001$ for archaea; $R=0.52, p<0.001$ for bacteria, Fig. S6). The OTUs of which relative abundance increased at the upper slope did not possess the genes for ammonia oxidation (Table 1). We could not analyze the change in their community composition because they were not detected
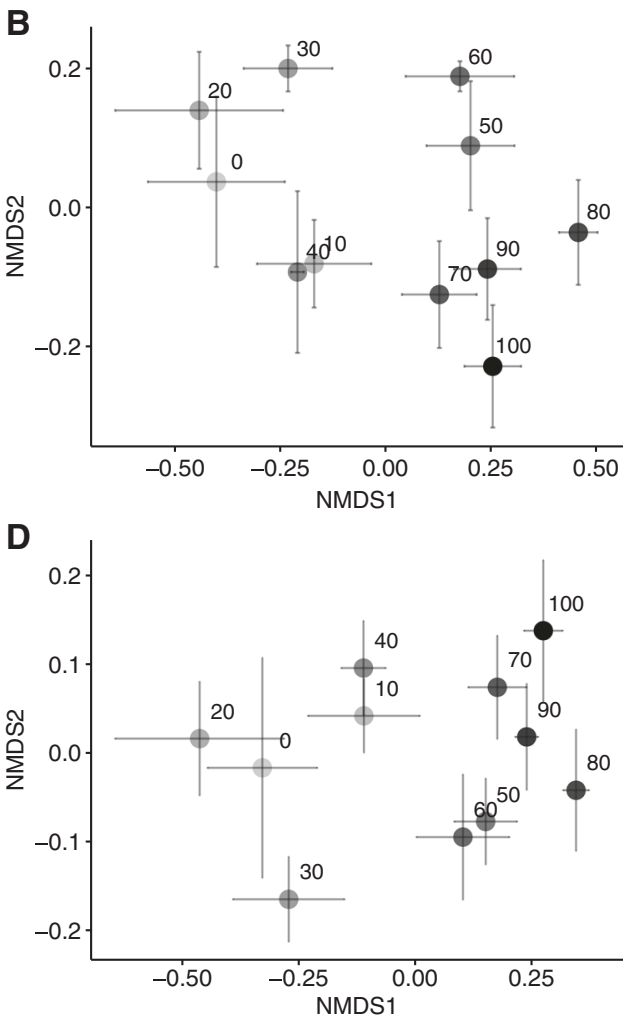

acetylglucosaminidase (b), arginase (c), and urease (d) along the forest slope. The numbers are the distances from the ridge $(\mathrm{m})$

along the upper slope (Fig. S6). Therefore, we compared the community composition based on amoA sequence clone libraries in the soils at the ridge and valley. The community composition of $\mathrm{NH}_{3}$-oxidizing archaea differed between the ridge and valley (Fig. S7). Archaeal amoA clones belonging to OTU_1, OTU_2, and OTU_6 were dominant at the ridge, whereas those belonging to OTU_2, OTU_3, OTU_4, and OTU_5 were dominant at the valley. Conversely, the community composition of $\mathrm{NH}_{3}$-oxidizing bacteria was similar (Fig. S7). Bacterial amoA clones belonging to OTU_1 were dominant at both the ridge and valley. Both archaeal and bacterial amoA OTUs that were dominant at the ridge were less abundant than the OTUs that were present at the valley (Fig. S7).

\section{Microbial responses to water manipulation}

The $\mathrm{NO}_{3}{ }^{-}$content of the soils taken at the valley increased with incubation time, whereas that of the soils taken at the ridge remained low (Fig. 5). The nitrate content of the soils taken at the ridge with water added increased starting on day 28 . By day 84 , the $\mathrm{NO}_{3}{ }^{-}$content of the valley soils or water-manipulated ridge soils was higher than that of the ridge soils $(p<0.05)$. Along with the soil $\mathrm{NO}_{3}{ }^{-}$content, the abundance of archaeal amoA remained high and low in the 


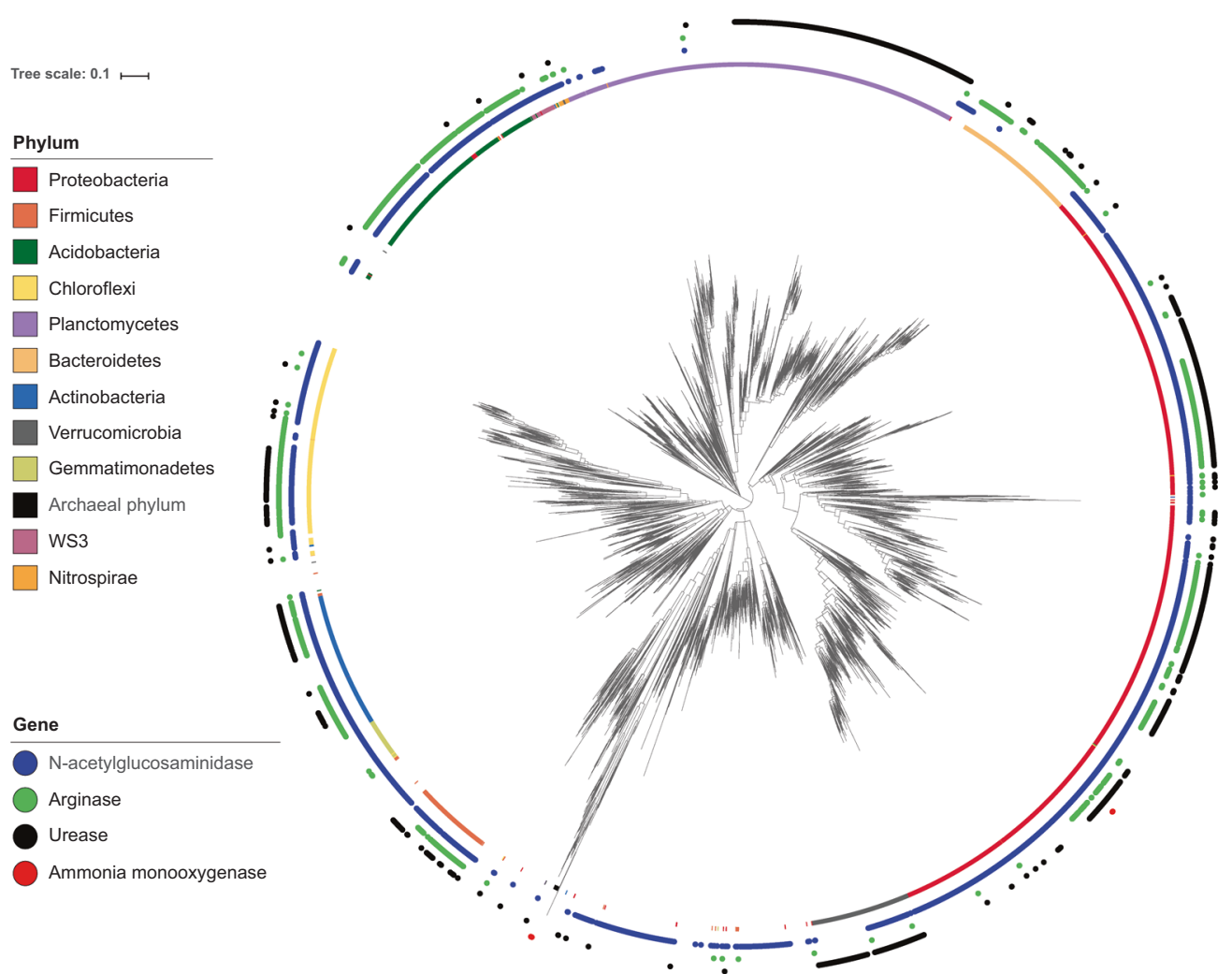

Fig. 4 Phylogenetic diversity of operational taxonomic units (OTUs) predicted to possess the genes for $N$-acetylglucosaminidase, arginase, and urease and identified as archaeal and bacterial ammonia oxidizers. These OTUs were mapped onto the phylogenetic tree of all OTUs

along the forest slope. The inner ring shows the taxonomy at the phylum level. The phylum with their abundance $>1 \%$ were illustrated. For a small portion of OTUs, taxonomic assignment did not match tree topology; however, no manual curation was attempted
Table 1 The number of OTUs predicted to possess the genes for ammonification and ammonia oxidation

\begin{tabular}{llllll}
\hline & Total & $N$-acetylglucosaminidase & Arginase & Urease & Ammonia monooxygenase \\
\hline Upper slope & 1159 & 774 & 410 & 482 & 0 \\
Lower slope & 2273 & 1407 & 691 & 631 & 5 \\
Nonlinear & 7219 & 4175 & 1752 & 1936 & 3 \\
\hline
\end{tabular}

OTUs were classified into three categories where their relative abundance increased at the upper or lower slope by exhibiting the linear relationships with the location on the forest slope (upper or lower slope) or did not increase significantly at either of upper or lower slope (nonlinear) $(p<0.1)$ soils at the valley and ridge, respectively, and increased from day 28 in the water-manipulated ridge soils $(R=0.94$, $p<0.001$ for the correlation between the soil $\mathrm{NO}_{3}{ }^{-}$content and abundance of archaeal amoA). On day 84, the abundances of archaeal amoA of the valley and watermanipulated ridge soils were higher than that of the ridge soils $(p<0.05)$. In contrast, the abundances of bacterial amoA and 16S rRNA gene of the valley soils had decreased, and they were comparable with those of the ridge and water-manipulated ridge soils.

From the 16S rRNA gene sequences rarefied to 13,000 sequences, 10,695 OTUs were obtained. The microbial community composition differed between the valley and ridge soils on day 0 (Fig. 5). The community composition of all soil sets did not shift significantly during the 84-day incubation. In particular, on day 84 , the community compositions of the ridge soils with and without water manipulation did not differ from each other, but they differed from that of the valley soils $(p<0.05)$.

\section{Discussion}

\section{Hierarchal relationship of soil environmental properties, microbial abundances, and $\mathrm{N}$ transformations}

We first analyzed the effects of the soil environmental gradient on gross ammonification and nitrification rates with the change in the abundance of ammonifiers (i.e., total 
A
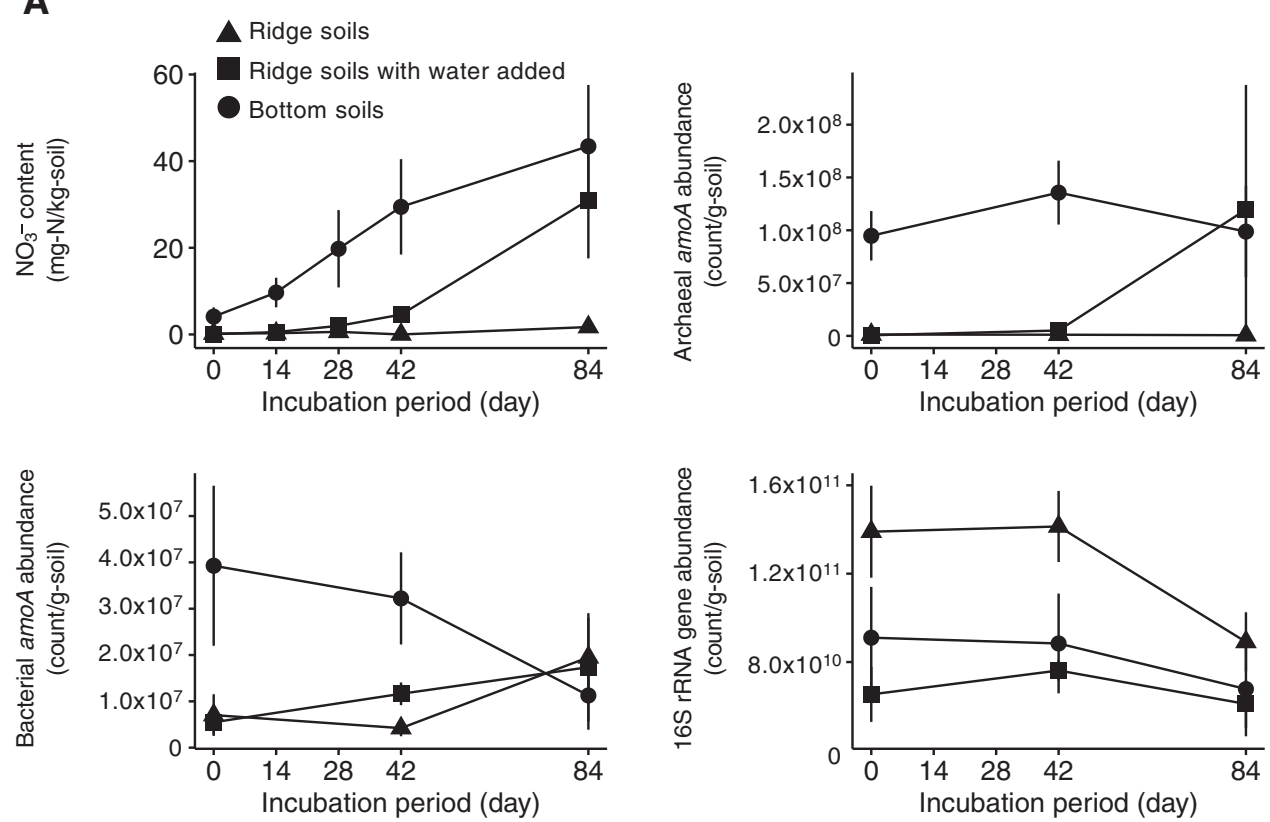

B

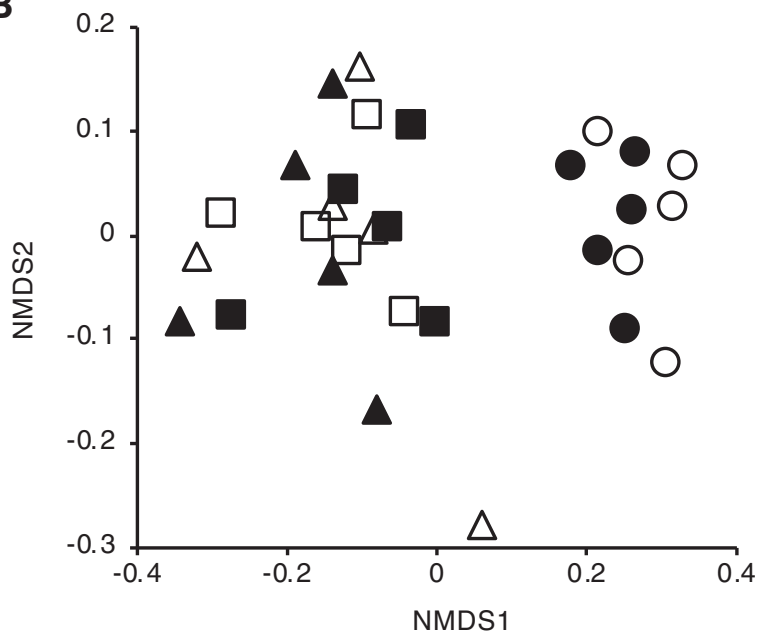

$\triangle$ Ridge soils (day 0)

$\triangle$ Ridge soils (day 84)

$\square$ Ridge soils with water added (day 0)

Ridge soils with water added (day 84)

Bottom soils (day 0 )

Bottom soils (day 84)

NMDS1

Fig. 5 Microbial responses to water manipulation. Nitrate content (a) and archaeal (b) and bacterial (c) amoA abundances in three soil sets: soils taken at the ridge (dry soils, $23 \%$ soil water content on average), soils taken at the valley (wet soils, $43 \%$ ), and soils taken at the ridge with water added to the same level as that in soils at the valley (wet soils, 43\%). Nonmetric multidimensional scaling ordination showing the change in the composition of the ammonifier (total microbial) community in the three soil sets during the 84-day incubation (d) bacteria or OTUs predicted to be responsible for ammonification) and nitrifiers. SEM illustrated the hierarchical relationship of these properties (Fig. 2).

The gross rate measurement showed that $\mathrm{NH}_{4}{ }^{+}$was produced at a constant rate at all slope positions but was oxidized to $\mathrm{NO}_{3}{ }^{-}$via nitrification only in the lower slope (Fig. 1). This can explain the different $\mathrm{N}$ species that accumulated along the upper and lower parts of the slope as illustrated by the net ammonification and nitrification rates; $\mathrm{NH}_{4}{ }^{+}$in the upper slope (0-40 $\mathrm{m}$ from the top) and $\mathrm{NO}_{3}{ }^{-}$in the lower slope (80-100 $\mathrm{m}$ from the top) (Fig. 1). These $\mathrm{N}$ transformations could be driven by the abundances of ammonifiers and nitrifiers. The abundance of ammonifiers and $\mathrm{NH}_{3}$ oxidizing archaea exhibited a similar change along the slope to the gross ammonification and nitrification rates, respectively (Fig. 1 and S5), and showed positive correlations with the corresponding process rates. $\mathrm{NH}_{3}$-oxidizing archaea seemed more substantially responsible for nitrification than $\mathrm{NH}_{3}$ oxidizing bacteria from the results of correlations (the abundance of archaeal amoA, not bacterial $a m o A$, correlated with nitrification rate) and the water manipulation experiment discussed below.

The abundances of both ammonifiers and nitrifiers were affected by soil water content, but the abundance of nitrifiers 
was more sensitive to changes in soil water content (Fig. 2). The higher sensitivity of the abundance of nitrifiers was further confirmed in the water manipulation experiment (Fig. 5). $\mathrm{NH}_{3}$-oxidizing archaea in the ridge soils responded positively to water manipulation, which was consistent with the increase in soil $\mathrm{NO}_{3}{ }^{-}$content. The enhancement of growth and nitrification activity of soil $\mathrm{NH}_{3}$-oxidizing archaea, not $\mathrm{NH}_{3}$-oxidizing bacteria, by the increase in water availability was also observed by Bustamante et al. [47].

Thus, we concluded that the gross ammonification and nitrification rates were affected by the abundances of ammonifiers and nitrifiers, respectively. The gross ammonification and nitrification rates were affected differently by the soil water gradient because of the lower sensitivity of abundance of ammonifiers and higher sensitivity of abundance of nitrifiers to the soil water gradient.

\section{Phylogenetic microbial diversity sustaining the stability of $\mathbf{N}$ transformations}

We then analyzed the effects of differences in the phylogenetic diversity of ammonifiers and nitrifiers on the stability of ammonification and nitrification rates. Microbial functional redundancy illustrates that even when the composition of a microbial community shifts in the face of environmental changes, the functions of a diverse community are less affected. This occurs because the diverse community is likely to possess taxa that are physiologically well-acclimated to the new environmental conditions and that can complement the functions of affected taxa [3, 15].

Our results suggested that the communities at the upper and lower slopes have different taxa of ammonifiers (Table 1 and Fig. 4), while the abundance of ammonifiers did not exhibit a consistent spatial change along the slope (Fig. 1 and S5). Their community composition was considered to be highly affected by the soil $\mathrm{pH}$. These suggests that different taxa could acclimate to the soil environmental conditions (particularity to soil $\mathrm{pH}$ ) at different locations along the slope and perform the same function of ammonification.

Conversely, nitrifiers on the slope might not include taxa that are physiologically acclimated to environments of the upper slope. Both archaeal and bacterial amoA OTUs that were dominant at the ridge were less abundant than the OTUs that were present at the valley (Fig. S7). Not only that but also $\mathrm{NH}_{3}$-oxidizing archaea and bacteria constituted the more minor group in the whole community at the ridge because they were not detected in the 17,800 rarefied sequences (Fig. S6). This suggests that the phylogenetic diversity of $\mathrm{NH}_{3}$-oxidizing archaea and bacteria at the ridge were strictly suppressed by the soil environmental conditions of the location. Gubry-Rangin et al. [48] studied the geography of $\mathrm{NH}_{3}$-oxidizing archaea and found that $\mathrm{NH}_{3}$ - oxidizing archaea in low-pH soils were phylogenetically less diverse and constituted the more minor group in the whole community than those in neutral-pH soils. We also found that only one amoA OTU was predominant in highly acidified forest soils [26]. Huang et al. [49] studied the archaeal geography and found that archaea in drier soils were phylogenetically less diverse. These findings suggest that $\mathrm{NH}_{3}$-oxidizing archaea, the main $\mathrm{NH}_{3}$-oxidizers in the soils, are less likely to possess taxa that prefer or adapt to low-pH and/or low-water-content soils in their phylogeny.

Thus, based on the results, we could expect that the larger phylogenetic diversity of ammonifiers facilitates the greater adaptability to new environments and thus the higher stability of the abundance of ammonifiers and ammonification rate against soil environmental changes.

\section{Functional role of microbial diversity in forest $\mathrm{N}$ cycling and plant growth}

We discuss the effects of the relationships among soil environmental properties, microbial abundances, microbial diversity, and $\mathrm{N}$ transformations on $\mathrm{N}$ availability to plants. As discussed above, the phylogenetic diversity of ammonifiers and nitrifiers could result in the spatial distribution of the $\mathrm{N}$ species available to plants (i.e., $\mathrm{NH}_{4}{ }^{+}$in the upper slope and $\mathrm{NO}_{3}{ }^{-}$in the lower slope). Previous studies conducted in other forests also showed similar spatial patterns of $\mathrm{NH}_{4}{ }^{+}$and $\mathrm{NO}_{3}{ }^{-}$along a slope [24, 50-53]. Further, the same tree species exhibited the different growth rates and $\mathrm{N}$ utilization patterns between the upper and lower slopes; the trees along the lower slope grew faster by utilizing $\mathrm{NO}_{3}{ }^{-}$, which is easily diffused in the soil matrix compared with $\mathrm{NH}_{4}{ }^{+}$, and abundant water whereas the trees along the upper slope were more likely to distribute their biomass to the belowground sections to take up $\mathrm{NH}_{4}{ }^{+}$and scarce water $[51,54,55]$. The tree species on the slope in our study site, namely, Cryptomeria japonica, also grew faster along the lower slope (see the Materials and methods section). This could be attributable to the higher availability of $\mathrm{NO}_{3}{ }^{-}$and water in the lower slope. The close relationship of spatial distributions of $\mathrm{N}$ availability and plant productivity in forest has been also reported in some studies [56, 57].

Based on the observations in previous studies and this work, we suggest that the diversity and spatial distribution of ammonifiers and nitrifiers could affect plant growth through the supply of $\mathrm{N}$ available to plants.

\section{Testing the functional role of microbial diversity in the field}

This study suggests that the response of microbial abundance that drives $\mathrm{N}$ cycling to environmental change can be affected by the phylogenetic diversity, which finally affects 
the productivity of plants in forests. The greater functional redundancy that we observed in this study was assumed to be an important function of microbial diversity for biogeochemical cycling [14], but this has rarely been tested in the field.

First, we have to distinguish the contributions of microbes and substrate supply to the corresponding ecosystem process. When comparing functional redundancy of functionally distinct microbial groups, the substrate supply by the precursive reaction can overshadow the difference in functional redundancy and thus needs to be carefully considered [58, 59]. For example, the denitrifiers' nirK abundance increased down the slope (Fig. 1), implying that the denitrification rate may increase down the slope. However, we could not consider the functional redundancy of denitrifiers that is more phylogenetically diverse than nitrifiers [37] as low as that of nitrifiers, because the abundance of denitrifiers could be limited by the substrate supply $\left(\mathrm{NO}_{3}{ }^{-}\right.$production by nitrifiers). Recent studies found that substrate availability could be more important than the denitrifiers' abundance for denitrification [30] and could affect the microbial diversity-function relationship of denitrifiers [60].

Second, we have to distinguish the contribution of microbial abundance and community composition (or diversity). Conversely, studies on microbial functional redundancy likely focused disproportionately on community composition (or diversity), which is less directly linked to the ecosystem process rates [29]. Further, microbial abundance and community composition may be regulated dominantly by different environmental factors. At our site, the community composition seemed affected strongly by soil $\mathrm{pH}$, whereas the abundance was affected more strongly by soil water content, as expected based on the results of correlations and the water manipulation experiment where the water input did not induce a compositional shift (Fig. 5). Recent studies show that bacterial preference for soil $\mathrm{pH}$ is more deeply conserved in their phylogeny than that for soil water content $[61,62]$, suggesting that change in soil $\mathrm{pH}$ alters the community composition more drastically than the change in soil water content. Bacterial biogeographic studies also show that soil $\mathrm{pH}$ could shape the community composition more dominantly than soil moisture (e.g. refs. [63-65]). On the other hand, soil water content might affect their abundance by controlling substrate supply to microbes by altering the solvability and diffusion rate of the substrates in soil matrix, as precisely examined in Stark and Firestone [66] with $\mathrm{NH}_{3}$ oxidizers in soil.

Previous studies investigating the microbial functional redundancy or microbial diversity-function relationship attempted to overcome these difficulties by manipulating the microbial diversity and abundance and adding the substrate [67]. These studies support the assumption that broad functions such as respiration and biomass production often seem more resistant to changes in community composition or diversity than narrow functions such as denitrification and degradation of specific compounds [9-11, 60, 68], with some exceptions [69]. However, these studies were limited mostly to laboratory incubation and short-term response of manipulated microbial community to the substrate input, which does not always reflect conditions in the field. We shed light on the microbial functional redundancy in the field and discussed its importance in ecosystem $\mathrm{N}$ cycling by focusing on functionally distinct microbial groups with contrasting ranges of phylogenetic diversity. We overcame the difficulties above by taking advantage of the distinct characteristics of the study site: the substrate for ammonifiers (soil DON content) and nitrifiers (soil $\mathrm{NH}_{4}{ }^{+}$content) did not seem to change along the slope (Fig. 1); and the chemical quality of litter may also not change significantly in the small-scale plot where a singleplanted tree species was distributed. Further, we used the steep slope of forests where the soil environmental properties and tree growth changed gradually, which allowed us to estimate the relationship between microbial abundance or community composition and soil environmental properties by simple correlations with the support of a manipulation experiment.

\section{Conclusion and implications for future research}

We demonstrated that the abundance of microbes possessing specialized functions directly affects the corresponding ecosystem process rates and that their diversity affects the stability of the process against environmental changes. By focusing on ammonifiers and nitrifiers in a forest, we further demonstrated that microbial diversity can contribute not only to ecosystem process rates but also to plant productivity.

The microbial functional redundancy may also be important when considering the ecosystem response to a changing environment. The effects of environmental change may be more likely to be evident in the microbial ecosystem processes that are performed by the less diverse or specified microbial taxa. In line with this, nitrification is known as a process sensitive to environmental change because of the large fluctuation of nitrifiers' abundance upon environmental disturbances [70]. We have also shown that ammonia-oxidizing archaea were sensitive to the ecological phenomena behind the forest $\mathrm{N}$ saturation although ammonifying activity was stable, which accordingly caused high $\mathrm{NO}_{3}^{-}$leaching from the forest [26]. Therefore, we suggest that microbial functional diversity is critical to improving terrestrial nitrogen models and predicting ecosystem responses to environmental change. 
We should note that this study has limitations and thus there is still room for improvement to clearly verify the ecosystem role of microbial diversity. For example, we did not study the fungal activity. Fungi may contribute to ammonification although their contribution is difficult to measure [71]. Further, arbuscular mycorrhizal fungi form symbiotic relationships with Cryptomeria japonica and may transfer $\mathrm{N}$, although the trees may take up most available $\mathrm{N}$ species in soils regardless of the presence of symbiotic mycorrhiza [72]. In addition, we generally measure ammonification in the form of ammonium production as a single process; however, it is actually the sum of multiple distinct physiological processes, in which multiple enzymes are involved. The relationship between taxonomy and production capabilities for those enzymes is obscure, which hinders the accurate estimation of PICRUSt. These limitations of this study need to be addressed in future studies and we need more study cases to highlight the contributions of microbial diversity and functional redundancy to biogeochemical cycling in an ecosystem.

\section{Data accessibility}

Raw sequence reads from Illumina Miseq were submitted to the DNA Data Bank of Japan (DDBJ) under accession number DRA007963. AmoA clone sequences were submitted to DDBJ under accession numbers LC492980-LC492999. Our analysis of the sequence dataset is available at https:// github.com/kazuo-isobe/forest_slope/.

Acknowledgements We thank Rieko Urakawa for hepling soil chemical analyses and Sydney I. Glassman for helpful comments on the manuscript. This study was financially supported by research funds of JSPS (26712015, 18H02233, and 18K05721). KI was supported by JSPS Overseas Research Fellowships (995308).

Author contributions KI, YI, HK, TO, CV and KK analyzed the data. $\mathrm{KI}, \mathrm{TO}$ and NO conceived and designed the analyses. KI wrote the paper with editorial contributions from KK, RT, KS and NO.

\section{Compliance with ethical standards}

Conflict of interest The authors declare that they have no conflict of interest.

Publisher's note: Springer Nature remains neutral with regard to jurisdictional claims in published maps and institutional affiliations.

Open Access This article is licensed under a Creative Commons Attribution 4.0 International License, which permits use, sharing, adaptation, distribution and reproduction in any medium or format, as long as you give appropriate credit to the original author(s) and the source, provide a link to the Creative Commons license, and indicate if changes were made. The images or other third party material in this article are included in the article's Creative Commons license, unless indicated otherwise in a credit line to the material. If material is not included in the article's Creative Commons license and your intended use is not permitted by statutory regulation or exceeds the permitted use, you will need to obtain permission directly from the copyright holder. To view a copy of this license, visit http://creativecommons. org/licenses/by/4.0/.

\section{References}

1. Maynard DS, Bradford MA, Lindner DL, van Diepen LTA, Frey SD, Crowther TW. Diversity begets diversity in competition for space. Nat Ecol Evol. 2017;1:156.

2. Shade A. Diversity is the question, not the answer. ISME J. 2017;11:1-6.

3. Shade A, Peter H, Allison SD, Baho DL, Berga M, Bürgmann H, et al. Fundamentals of microbial community resistance and resilience. Front Microbiol. 2012;3:1-19.

4. Louca S, Polz M, Mazel F, Albright M, Julie H, O'Connor M, et al. Function and functional redundancy in microbial systems. Nat Ecol Evol, 2018;2:936-43.

5. Bissett A, Brown MV, Siciliano SD, Thrall PH. Microbial community responses to anthropogenically induced environmental change: towards a systems approach. Ecol Lett. 2013;16:128-39.

6. Balvanera P, Pfisterer AB, Buchmann N, He JS, Nakashizuka T, Raffaelli $\mathrm{D}$, et al. Quantifying the evidence for biodiversity effects on ecosystem functioning and services. Ecol Lett. 2006;9:1146-56.

7. Tilman D. The ecological consequences of changes in biodiversity: a search for general principles. Ecology. 1999;80:1455-74.

8. Zavaleta ES, Pasari JR, Hulvey KB, Tilman GD. Sustaining multiple ecosystem functions in grassland communities requires higher biodiversity. Proc Natl Acad Sci. 2010;107:1443-6.

9. Girvan MS, Campbell CD, Killham K, Prosser JI, Glover LA. Bacterial diversity promotes community stability and functional resilience after perturbation. Environ Microbiol. 2005;7:301-13.

10. Peter H, Beier S, Bertilsson S, Lindström ES, Langenheder S, Tranvik LJ. Function-specific response to depletion of microbial diversity. ISME J. 2011;5:351-61.

11. Trivedi C, Delgado-Baquerizo M, Hamonts K, Lai K, Reich PB, Singh BK. Losses in microbial functional diversity reduce the rate of key soil processes. Soil Biol Biochem. 2019;135:267-74.

12. Falkowski PG, Fenchel T, Delong EF. The microbial engines that drive earth's biogeochemical cycles. Sci. 2008;320:1034-9.

13. Isobe $\mathrm{K}$, Ohte $\mathrm{N}$. Ecological perspectives on microbes involved in N-cycling. Microbes Environ. 2014;29:4-16.

14. Schimel J. Ecosystem consequences of microbial diversity and community structure. Arctic and alpine biodiversity: patterns, causes and ecosystem consequences. Berlin, Heidelberg: Springer; 1995. p. 239-54.

15. Allison SD, Martiny JBH. Resistance, resilience, and redundancy in microbial communities. Proc Natl Acad Sci. 2008;105:11512-9.

16. Delgado-Baquerizo M, Maestre FT, Reich PB, Jeffries TC, Gaitan JJ, Encinar D, et al. Microbial diversity drives multifunctionality in terrestrial ecosystems. Nat Commun. 2016b;7:10541-8.

17. Vitousek P, Howarth R. Nitrogen limitation on land and in the sea: How can it occur? Biogeochemistry. 1991;13:87-115.

18. Myrold DD, Bottomley PJ. Nitrogen mineralization and immobilization. In: Raun W, Schepers, JS, editors. Nitrogen in agricultural soils. Madison, WI: American Society of Agronomy; 2008. p. 157-72.

19. Schimel JP, Bennett JB. Nitrogen mineralization: challenges of a changing paradigm. Ecology. 2004;85:591-602.

20. Bottomley PJ, Taylor AE, Myrold DD. A consideration of the relative contributions of different microbial subpopulations to the soil N cycle. Front Microbiol. 2012;3:1-7.

21. Daims H, Lebedeva EV, Pjevac P, Han P, Herbold C, Albertsen $\mathrm{M}$, et al. Complete nitrification by Nitrospira bacteria. Nature. 2015;528:504-9. 
22. Prosser JI, Nicol GW. Archaeal and bacterial ammonia-oxidisers in soil: the quest for niche specialisation and differentiation. Trends Microbiol. 2012;20:523-31.

23. Trivedi P, Delgado-Baquerizo M, Trivedi C, Hu H, Anderson IC, Jeffries TC, et al. Microbial regulation of the soil carbon cycle: evidence from gene-enzyme relationships. ISME J. 2016; 10:2593-604.

24. Isobe K, Ohte N, Oda T, Murabayashi S, Wei W, Senoo K, et al. Microbial regulation of nitrogen dynamics along the hillslope of a natural forest. Front Environ Sci. 2015;2:1-8.

25. Hawkes CV, Wren IF, Herman DJ, Firestone MK. Plant invasion alters nitrogen cycling by modifying the soil nitrifying community. Ecol Lett. 2005;8:976-85.

26. Isobe K, Ikutani J, Fang Y, Yoh M, Mo J, Suwa Y, et al. Highly abundant acidophilic ammonia-oxidizing archaea causes high rates of nitrification and nitrate leaching in nitrogen-saturated forest soils. Soil Biol Biochem. 2018a;122:220-7.

27. Isobe K, Koba K, Suwa Y, Ikutani J, Fang Y, Yoh M, et al. High abundance of ammonia-oxidizing archaea in acidified subtropical forest soils in southern China after long-term $\mathrm{N}$ deposition. FEMS Microbiol Ecol. 2012;80:193-203.

28. Philippot L, Čuhel J, Saby NPA, Chèneby D, Chroňáková A, Bru D, et al. Mapping field-scale spatial patterns of size and activity of the denitrifier community. Environ Microbiol. 2009;11:1518-26.

29. Bier RL, Bernhardt ES, Boot CM, Graham EB, Hall EK, Lennon JT, et al. Linking microbial community structure and microbial processes: an empirical and conceptual overview. FEMS Microbiol Ecol. 2015;91:fiv113.

30. Graham EB, Knelman JE, Schindlbacher A, Siciliano S, Breulmann M, Yannarell A, et al. Microbes as engines of ecosystem function: when does community structure enhance predictions of ecosystem processes? Front Microbiol. 2016;7:1-10.

31. Oda T, Imamura N, Egusa T, Ohte N. The effects of canopy alteration-induced atmospheric deposition changes on stream chemistry in Japanese cedar forest. For Ecol Manag. 2019;448:85-93.

32. Nishizono T, Zushi K, Hiroshima T, Toyama K, Kitahara F, Terada $\mathrm{F}$, et al. Latitudinal variation in radial growth phenology of Cryptomeria japonica D. Don trees in Japan. Forestry. 2018;91:206-16.

33. Hart SC, Stark JM, Davidson EA, Firestone MK. Nitrogen mineralization, immobilization, and nitrification. In: Weaver RW, Angle C, Bottomley P, Bezdicek D, Smith S, Tabatabai A, Wollum A (Eds). Methods of soil analysis: part 2-microbiological and biochemical properties. Soil Science Society of America; 1994. Soil Science Society of America, Madison, WI. p. 985-1018.

34. Isobe K, Koba K, Otsuka S, Senoo K. Nitrification and nitrifying microbial communities in forest soils. J Res. 2011a;16:193-203.

35. Urakawa R, Ohte N, Shibata H, Tateno R, Hishi T, Fukushima K, et al. Biogeochemical nitrogen properties of forest soils in the Japanese archipelago. Ecol Res. 2015;30:1-2.

36. Isobe K, Suwa Y, Ikutani J, Kuroiwa M, Makita T, Takebayashi $\mathrm{Y}$, et al. Analytical techniques for quantifying $15 \mathrm{~N} / 14 \mathrm{~N}$ of nitrate, nitrite, total dissolved nitrogen and ammonium in environmental samples using a gas chromatograph equipped with a quadrupole mass spectrometer. Microbes Environ. 2011b;26:46-53.

37. Wei W, Isobe K, Nishizawa T, Zhu L, Shiratori Y, Ohte N, et al. Higher diversity and abundance of denitrifying microorganisms in environments than considered previously. ISME J. 2015; 9:1954-65.

38. Isobe $\mathrm{K}$, Oka $\mathrm{H}$, Watanabe $\mathrm{T}$, Tateno $\mathrm{R}$, Urakawa $\mathrm{R}$, Liang $\mathrm{C}$, et al. High soil microbial activity in the winter season enhances nitrogen cycling in a cool-temperate deciduous forest. Soil Biol Biochem. 2018b;124:90-100.
39. Caporaso JG, Lauber CL, Walters WA, Berg-Lyons D, Lozupone CA, Turnbaugh PJ, et al. Global patterns of $16 \mathrm{~S}$ rRNA diversity at a depth of millions of sequences per sample. Proc Natl Acad Sci. 2011;108:4516-22.

40. Edgar RC. UPARSE: highly accurate OTU sequences from microbial amplicon reads. Nat Methods. 2013;10:996-8.

41. Caporaso JG, Kuczynski J, Stombaugh J, Bittinger K, Bushman FD, Costello EK, et al. QIIME allows analysis of high-throughput community sequencing data. Nat Methods. 2010;7:335-6.

42. Langille M, Zaneveld J, Caporaso JG, McDonald D, Knights D, Reyes J, et al. Predictive functional profiling of microbial communities using $16 \mathrm{~S}$ rRNA marker gene sequences. Nat Biotechnol. 2013;31:814-21.

43. Fujii K, Yamada T, Hayakawa C, Nakanishi A, Funakawa S. Another bottleneck for nitrogen mineralization in temperate forest soils: arginine metabolism in microorganisms. Soil Biol Biochem. 2018;126:22-30.

44. Zimmerman AE, Martiny AC, Allison SD. Microdiversity of extracellular enzyme genes among sequenced prokaryotic genomes. ISME J. 2013;7:1187-99.

45. Eisenhauer N, Bowker MA, Grace JB, Powell JR. From patterns to causal understanding: Structural equation modeling (SEM) in soil ecology. Pedobiologia. 2015;58:65-72.

46. Urakawa R, Ohte N, Shibata H, Isobe K, Tateno R, Oda T, et al. Factors contributing to soil nitrogen mineralization and nitrification rates of forest soils in the Japanese archipelago. Ecol Manag. 2016;361:382-96.

47. Bustamante M, Verdejo V, Zúñiga C, Espinosa F, Orlando J, Carú M. Comparison of water availability effect on ammonia-oxidizing bacteria and archaea in microcosms of a Chilean semiarid soil. Front Microbiol. 2012;3:1-10.

48. Gubry-Rangin C, Hai B, Quince C, Engel M, Thomson BC, James $\mathrm{P}$, et al. Niche specialization of terrestrial archaeal ammonia oxidizers. Proc Natl Acad Sci USA. 2011;108:21206-11.

49. Huang M, Chai L, Jiang D, Zhang M, Zhao Y, Huang Y. Increasing aridity affects soil archaeal communities by mediating soil niches in semi-arid regions. Sci Total Environ. 2019;647: 699-707.

50. Hirobe M, Tokuchi N, Iwatsubo G. Spatial variability of soil nitrogen transformation patterns along a forest slope in a Cryptomeria japonica D. Don plantation. Eur J Soil Biol. 1998;34:123-31.

51. Koyama L, Hirobe M, Koba K, Tokuchi N. Nitrate-use traits of understory plants as potential regulators of vegetation distribution on a slope in a Japanese cedar plantation. Plant Soil. 2013;362:119-34

52. Tateno R, Takeda H. Forest structure and tree species distribution in relation to topography-mediated heterogeneity of soil nitrogen and light at the forest floor. Ecol Res. 2003;18:559-71.

53. Tokuchi N, Hirobe M, Koba K. Topographical differences in Soil $\mathrm{N}$ transformation using ${ }^{15} \mathrm{~N}$ dilution method along a slope in a conifer plantation forest in Japan. J Res. 2000;5:13-9.

54. Tateno R, Osada N. Inorganic nitrogen source utilization by Fagus crenata on different soil types. Trees. 2005;19:477-81.

55. Tateno R, Takeda H. Nitrogen uptake and nitrogen use efficiency above and below ground along a topographic gradient of soil nitrogen availability. Oecologia. 2010;163:793-804.

56. Diwold K, Dullinger S, Dirnböck T. Effect of nitrogen availability on forest understorey cover and its consequences for tree regeneration in the Austrian limestone Alps. Plant Ecol. 2010;209:11-22.

57. Bengtson P, Falkengren-Grerup U, Bengtsson G. Spatial distributions of plants and gross $\mathrm{N}$ transformation rates in a forest soil. J Ecol. 2006;94:754-64.

58. Luizao RCC, Luizao FJ, Paiva RQ, Monteiro TF, Sousa LS, Kruijt B. Variation of carbon and nitrogen cycling processes along a 
topographic gradient in a central Amazonian forest. Glob Chang Biol. 2004;10:592-600.

59. Bohlen PJ, Groffman PM, Driscoll CT, Fahey TJ, Siccama TG. Plant-soil-microbial interactions in a Northern Hardwood Forest. Ecology. 2001;82:965-78.

60. Philippot L, Spor A, Hénault C, Bru D, Bizouard F, Jones CM, et al. Loss in microbial diversity affects nitrogen cycling in soil. ISME J. 2013;7:1609-19.

61. Martiny AC, Treseder K, Pusch G. Phylogenetic conservatism of functional traits in microorganisms. ISME J. 2013;7:830-8.

62. Martiny JBH, Jones SE, Lennon JT, Martiny AC. Microbiomes in light of traits: a phylogenetic perspective. Sci. 2015;350: aac9323-aac9323.

63. Griffiths RI, Thomson BC, James P, Bell T, Bailey M, Whiteley AS. The bacterial biogeography of British soils. Environ Microbiol. 2011;13:1642-54.

64. Lauber CL, Hamady M, Knight R, Fierer N. Pyrosequencingbased assessment of soil $\mathrm{pH}$ as a predictor of soil bacterial community structure at the continental scale. Appl Environ Microbiol. 2009;75:5111-20.

65. Lauber CL, Strickland MS, Bradford MA, Fierer N. The influence of soil properties on the structure of bacterial and fungal communities across land-use types. Soil Biol Biochem. 2008;40: $2407-15$.
66. Stark J, Firestone MK. Mechanisms for soil moisture effects on activity of nitrifying bacteria. Appl Environ Microbiol. 1995; 61:218-21.

67. Loreau M, Naeem S, Inchausti P, Bengtsson J, Grime JP, Hector A, et al. Biodiversity and ecosystem functioning: current knowledge and future challenges. Science. 2001;294:804-8.

68. Singh BK, Quince C, Macdonald CA, Khachane A, Thomas N, Al-Soud WA, et al. Loss of microbial diversity in soils is coincident with reductions in some specialized functions. Environ Microbiol. 2014;16:2408-20.

69. Delgado-Baquerizo M, Giaramida L, Reich PB, Khachane AN, Hamonts K, Edwards C, et al. Lack of functional redundancy in the relationship between microbial diversity and ecosystem functioning. J Ecol. 2016a;104:936-46.

70. Graham DW, Knapp CW, Van Vleck ES, Bloor K, Lane TB, Graham CE. Experimental demonstration of chaotic instability in biological nitrification. ISME J. 2007;1:385-93.

71. Boyle SA, Yarwood RR, Bottomley PJ, Myrold DD. Bacterial and fungal contributions to soil nitrogen cycling under Douglas fir and red alder at two sites in Oregon. Soil Biol Biochem. 2008;40:443-51.

72. Takebayashi Y, Koba K, Sasaki Y, Fang Y, Yoh M. The natural abundance of $15 \mathrm{~N}$ in plant and soil-available $\mathrm{N}$ indicates a shift of main plant $\mathrm{N}$ resources to $\mathrm{NO}_{3}{ }^{-}$from $\mathrm{NH}_{4}{ }^{+}$along the $\mathrm{N}$ leaching gradient. Rapid Commun Mass Spectrom. 2010;24:1001-8. 